\title{
Impact of Usage of Different Coping Strategies on Academic Performance of Female Students in College of Medicine, Al-Ahsa Manal Ali Saleh Baaleis ${ }^{1}$, Sayed Ibrahim Ali*2 \\ 1. Medical Intern, College of Medicine, King Faisal University, Saudi Arabia \\ 2. Assistant Professor, College of Medicine, King Faisal University, Saudi Arabia, and Lecturer, College of Education, Helwan University, Egypt \\ *corresponding author: Sayed Ibrahim Ali, Email: drsamas38@ gmail.com
}

\begin{abstract}
Background: academic stress can be prescribed as mental distress with respect to some anticipated frustration associated with academic failure or even awareness of the possibility of such failure. Medicine in specific is one of the most stressful fields of education because of its highly demanding professional and academic requirements, highly extensive medical curricula, repeated difficult exams and fear of failure all are causes of persistent stress and anxiety for medical students. Student's ability to handle these increasing demands of medical school can affect their academic success and emotional health. Experiencing stress and anxiety is beneficial to some extent as it can enhance the academic performance. In the other hand, increasing levels of stress that students exposed may have a negative effect on their cognitive functioning and learning abilities in the medical school. Coping is an important key point of dealing with stress and preventing psychological problems.

Aim of the work: this study explored the impact of usage of different coping strategies on academic performance of students of College of Medicine in Al-Ahsa, 2018 and which type they use more than the other and which of these different strategies comprise more satisfaction than the others do. Methods: this was a cross sectional study was carried out among female students in college of medicine in king Feisal University in the academic year 2017-2018. Data had been collected by electronic and paper survey, which contained demographics, educational level, family income, GPA, studying hours and the Lazarus's ways of coping framework, which was a widely accepted model containing 66 points that distinguishes between distinct active and emotion based coping methods. Results: 73 students were completed the survey, $58.9 \%$ of them reported being upsetlsad for significant amount in 2 weeks period, and $49.3 \%$ of students report that they feel they need psychiatric consultation. No significant association was noticed between GPA and each of coping strategies addressed in this study. Positive reappraisal was the most used strategy by $76.86 \%$, while confrontive coping was the least to use by $55.83 \%$.

Conclusion: medical students were more vulnerable to academic stress due to highly demanding professional and academic requirements. To overcome this, students used different coping strategies. According to our study, there was no significant impact on the GPA or difference between these strategies.
\end{abstract}

Keywords: Coping Strategies, Academic Performance, Female Students, College of Medicine, AlAhsa

\section{Introduction:}

Academic stress is described as mental distress with respect to some anticipated frustration associated with academic failure or even awareness of the possibility of such failure ${ }^{(\mathbf{1})}$. Medicine in specific is one of the most stressful fields of education because of its highly demanding professional and academic requirements. Several factors were responsible for this; we can classify them into two categories: academic stressors and nonacademic stressors. Academic stressors like facing difficulties in learning new medical words, difficulties in reading long textbooks especially if there is no preparatory year to prepare students for these new terminologies, overloading with medical tasks and assignments, extensive medical curricula, long studying hours, lack of support from health experts or family, poor quality of the educational process at the college, irregular busy schedules, huge number of exams, tough competition with peers and fear of failure $^{(2,3)}$. Non-academic stressors have two sub categories: psychosocial stressors which include: high family expectations, home sickness, new living circumstances, financial problems, fear of future failure in medical career. Socio-demographic stressors include: gender, smoking, substance use, marital status, working during the study, parents' level of 
education, cultural background and the family income ${ }^{(2,3)}$. Several studies carried out among medical students in the United States suggested that the practice of medicine can be considered as a risk factor affecting mental health of both qualified physicians and students and an association between the training and future mental health problem have been proposed by the same studies (4,5). Student's ability to handle these increasing demands of medical school can affect their academic success and emotional health ${ }^{(6)}$. The huge tasks that the student should do leave a minimal opportunity for the student to relax and recreate ${ }^{(7)}$. The estimated prevalence of emotional exhaustion found in different studies on medical students to be higher than that in the general population. In three British universities, the prevalence of stress was $31.2 \%^{(8)}$ and it was $41.9 \%$ in a Malaysian Medical School ${ }^{(9)}$ and $61.4 \%$ in a Thai Medical School ${ }^{(\mathbf{1 0})}$. Any level of persistent stress can produce effects such as sleeping problems, burnout, a drop out, a fact presented by Dyrbye et al. in their study (7). According to a study which was done in Egyptian medical students, the prevalence of psychological stress was $59.9 \%$ and consequently depression was $65 \%$ and anxiety was $73 \%$, also high scores of DASS 21 subscales and poor sleep quality were reported across the students of all academic years of medical school ${ }^{(3)}$. Coping is an important key point of dealing with stress and preventing psychological problems ${ }^{(6)}$. We can define coping as the individual ability to deal with external or internal requirements, which are beyond his resources by persistently changing his cognitive and behavioral efforts. It has mainly two actions: controlling feeling which are associated with the situation and changing the environment or the situation itself that cause the distress for the person. There are three characteristics describe this definition, the first one is it is a process oriented which means that it emphasizes on what the individual considers in his mind and what he is doing in a stressful situation. The second feature is that coping is contextual which means that the person evaluates the stressful event, what is the actual demand from it and what are the resources that are available to manage it. The last feature about this definition that there is no supposition about what person do, as there are no good or bad coping strategies ${ }^{\mathbf{( 1 1})}$.

Numerous researchers have attempted to identify groups of coping strategies ${ }^{(\mathbf{1 2})}$. In an early attempt to categorize specific coping strategies, they defied coping strategies into two categories: problem-focused coping strategies which refer to the actions done by the person in order to change the stressful situation or reduce the stress associated with it, whereas emotion-focused coping strategies refer to person endeavor to change the feelings that are associated with the stressful situation, without any effort to work on the situation itself ${ }^{(11)}$. The $1^{\text {st }}$ type of coping strategies usually lead to greater life satisfaction. On the other hand, usage of emotion centered coping mechanisms has been shown to be associated with the experience of distress and depression (13). There are eight coping strategies that individuals use to challenge stress distributed between the previously mentioned categories. Confrontive coping, seeking social support, planful problem-solving, and positive reappraisal are considered as problem-focused coping strategies while escape-avoidance, distancing, self-control and accepting responsibility are considered emotion-focused coping strategies ${ }^{(11)}$.

\section{Significance of the study:}

As the medical students are under increasing pressure due to several factors which included overloading of information, limited amount of time, repeated exams, high family expectations, sleep deprivation, isolation, overbearing clerical and administrative responsibilities, lack of support from allied health professionals or family, many patients to face with different personalities, and conditions for learning that are less than optimal.

Under these circumstances, students are exposed to many mental health problems like anxiety, depression and burn out which may lead them eventually to failure and leaving medical school if they don't cope with these huge number of stressors in a good manner. For students to cope in a good way, we should study these strategies and discover which of them has more benefits for the students and comprise more satisfaction than the others. 


\section{Methodology: \\ Study design:}

A cross sectional study

\section{Study population:}

Female students in College of Medicine in king Faisal University, academic year 2017-2018

\section{Inclusion criteria:}

Included being a female student studying in the college of medicine of king Faisal university, the educational level should be from the $1^{\text {st }}$ year to the internship year.

\section{Exclusion criteria:}

Male students and female students in the preparatory year had been excluded because of the difficulty to reach them also the preparatory year does not consider as a one of medical school years.

\section{Sample size:}

The sample size (n) for this study had been calculated by using the formula $\mathrm{n}=\mathrm{Z} 2 \times \mathrm{p}$ $\times \mathrm{q} / \mathrm{d} 2$. The estimated sample size was 252 students and only 77 students responded to the survey and only 73 of them complete the whole survey due to shortage of time and human resources.

\section{Sample collection technique:}

Data had been collected by electronic and paper survey distributed using the email and manually in the college.

\section{Research tools:}

An electronic and paper survey which contained demographics, educational level, family income, GPA, studying hours and the Lazarus's ways of coping framework which is a widely accepted model containing 66 points that distinguishes between four distinct active methods (Seeking Social Support, Planful Problem Solving, Confrontive Coping, and Positive Reappraisal) and four distinct emotional methods (Escape Avoidance, Distancing, Self-Control, and Accepting Responsibility). These points were rated according to 4 points Likert scale $(0=$ not used, 1=used somewhat, $2=$ used quite a bit, $3=$ used great deal). The survey was checked by ten psychiatrists for audit and to make sure of its availability to free use. Later, the survey was translated by the researcher to the Arabic language then checked by a psychologist for correction of translation. Students from all levels of medical school were invited to complete the survey.

\section{Statistical analysis:}

SPSS 25 used for the statistical applications. Descriptive statistics were used for the analysis of the basic demographics and survey items of the questionnaire. Chi square test used to explore the relationship between the sociodemographic and the coping strategies.

\section{Ethical considerations:}

Informed consent had been taken orally and written from all participants by the researcher and the researcher has explained the purpose from the study to all respondents. Confidentiality and privacy are guaranteed and maintained for each participant. The scale used in this study was cited and the reference has been written at the end of the article.

\section{Results:}

In total, 73 students completed the survey all of them were Saudi citizens. Their mean age was $22.34 \pm 1.988$ standard deviation years. $67 . \%$ of the sample were single while, $32.9 \%$ were married. From those who were married, only $20.5 \%$ had children. Regarding income, $54.8 \%$ had an income more than $10000,39.7 \%$ the income for them was between 5000 to 10000 and only $5.5 \%$ less than 5000 riyals. Regarding family type, $58.9 \%$ were living in a nuclear family and the other $41.1 \%$ were living in joint family. The distribution of students on the years was as following $17.8 \%, 6.8, \% 27.4 \%, 12.3 \%, 11 \%$ and $24.7 \%$ on $1^{\text {st }}, 2^{\text {nd }}, 3^{\text {rd }}, 4^{\text {th }}, 5^{\text {th }}$ and internship year respectively. The characteristics of the study subjects were shown in detail in table 1 . 
Impact of Usage of Different Coping Strategies on Academic Performance of Female Students...

\begin{tabular}{|c|c|c|}
\hline \multicolumn{2}{|c|}{ Table 1: frequencies and percentages for the demographic data } \\
\hline Study variable & No. & \% \\
\hline Marital status & 49 & \\
Single & 24 & 67.1 \\
Married & 15 & 32.9 \\
\hline Married with children & 58 & \\
Yes & & 20.5 \\
No & 4 & 79.5 \\
\hline Average family income & 29 & \\
Less than 5000 & 40 & 5.5 \\
From 5000 to 10000 & & 39.7 \\
More than 10000 & 43 & 54.8 \\
\hline Family type & 30 & \\
Nuclear family & & 58.9 \\
Joint family & 13 & 41.1 \\
\hline Year of study & 5 & \\
$1^{\text {st }}$ year & 20 & 17.8 \\
$2^{\text {nd }}$ year & 9 & 6.8 \\
$3^{\text {rd }}$ year & 8 & 27.4 \\
$4^{\text {th }}$ year & 18 & 12.3 \\
$5^{\text {th }}$ year & & 11 \\
Internship & & \\
\hline
\end{tabular}

The average studying hours of the student sample was approximately one half from three to five hours as it shown in table 2. Regarding the GPA it more than $36 \%$ were having a GPA above 4.00 and $36.9 \%$ had a GPA between 3.00 and 4.00 .

\begin{tabular}{|c|c|c|}
\hline \multicolumn{2}{|c|}{ Table 2: average of studying hours of the subjects and GPA } \\
\hline Variable & No. & $\%$ \\
\hline Studying hours & & \\
Less than 3 hours & 11 & 15.1 \\
From 3 to 5 hours & 37 & 50.7 \\
More than 5 hours & 25 & 34.2 \\
\hline GPA & 16 & \\
A+ & 30 & 21.9 \\
A & 25 & 41.1 \\
B+ & 2 & 34.2 \\
B & & 2.7 \\
\hline
\end{tabular}

According to the results in our study, $58.9 \%$ reported being upsetlsad for significant amount in 2 weeks period, $21.9 \%$ were not sure about their feelings and $19.2 \%$ only didn't report any sad feelings. And regarding seeking mental health expert consultation, $49.3 \%$ of students reported that they feel that they need psychiatric consultation, $6.8 \%$ were not sure about that and $43.8 \%$ didn't report psychiatric consultation need.

Regarding the use of different coping strategies which is shown in table 3

\begin{tabular}{|c|c|c|c|c|c|c|c|c|}
\hline \multicolumn{9}{|c|}{$\begin{array}{l}\text { Table 3: } 66 \text { points Lazurus and Folkman strategies percentage of use : } \\
\text { Problem based Strategies }\end{array}$} \\
\hline \multirow[t]{2}{*}{ 1.Confrontive coping: } & \multicolumn{2}{|c|}{ Not used } & \multicolumn{2}{|c|}{$\begin{array}{l}\text { Used } \\
\text { somewhat }\end{array}$} & \multicolumn{2}{|c|}{$\begin{array}{l}\text { Used a quite } \\
\text { bit }\end{array}$} & \multicolumn{2}{|c|}{$\begin{array}{l}\text { Used a grea } \\
\text { deal }\end{array}$} \\
\hline & No. & $\%$ & No. & $\%$ & No. & \% & No. & $\%$ \\
\hline $\begin{array}{l}\text { 6.I did something which I didn't think would } \\
\text { work, but at least I was doing something }\end{array}$ & 14 & 19.2 & 27 & 37 & 27 & 37 & 5 & 6.8 \\
\hline $\begin{array}{l}\text { 7.Tried to get the person responsible to change } \\
\text { his or her mind }\end{array}$ & 33 & 45.2 & 21 & 28.8 & 17 & 23.2 & 2 & 2.7 \\
\hline $\begin{array}{l}\text { 17.I expressed anger to the person(s) who caused } \\
\text { the problem }\end{array}$ & 28 & 38.4 & 22 & 30.1 & 14 & 19.2 & 9 & 12.3 \\
\hline 28.I let my feelings out somehow & 14 & 19.2 & 22 & 30.1 & 23 & 31.5 & 14 & 19.2 \\
\hline
\end{tabular}




\begin{tabular}{|c|c|c|c|c|c|c|c|c|}
\hline 34.Took a big chance or did something very risky & 39 & 53.4 & 14 & 19.2 & 15 & 20.5 & 5 & 6.8 \\
\hline $\begin{array}{l}\text { 46.Stood my ground and fought for what I } \\
\text { wanted }\end{array}$ & 9 & 12.3 & 15 & 20.5 & 26 & 35.6 & 23 & 31.5 \\
\hline \multicolumn{9}{|l|}{ 2.Seeking social support } \\
\hline $\begin{array}{l}\text { 8.Talked to someone to find out more about the } \\
\text { situation }\end{array}$ & 17 & 23.3 & 16 & 21.9 & 27 & 37 & 13 & 17.8 \\
\hline $\begin{array}{l}\text { 18. Accepted sympathy and understanding from } \\
\text { someone }\end{array}$ & 19 & 26 & 19 & 26 & 24 & 32.9 & 11 & 15.1 \\
\hline 22. I got professional help & 54 & 74 & 11 & 15.1 & 6 & 8.2 & 2 & 2.7 \\
\hline $\begin{array}{l}\text { 31. Talked to someone who could do something } \\
\text { concrete about the problem }\end{array}$ & 21 & 28.8 & 25 & 34.2 & 17 & 23.3 & 10 & 13.7 \\
\hline $\begin{array}{l}\text { 42. I asked a relative or friend I respected for } \\
\text { advice }\end{array}$ & 19 & 26 & 17 & 23.3 & 23 & 31.5 & 4 & 19.2 \\
\hline 45.Talked to someone about how I was feeling & 12 & 16.4 & 16 & 21.9 & 26 & 35.6 & 19 & 26 \\
\hline \multicolumn{9}{|l|}{ 3.Planful problem solving } \\
\hline 1. Just concentrated on what I had to do next & 4 & 5.5 & 13 & $\begin{array}{l}17.8 \\
\end{array}$ & 37 & 50.7 & 19 & 26 \\
\hline 26.I made a plan of action and followed it & 9 & 12.3 & 21 & 28.8 & 25 & 34.2 & 18 & 24.7 \\
\hline $\begin{array}{l}\text { 39. Changed something so things would turn out } \\
\text { all right }\end{array}$ & 9 & 12.3 & 18 & 24.7 & 30 & 41.1 & 16 & 21.9 \\
\hline $\begin{array}{l}\text { 48. Drew on my past experiences; I was in a } \\
\text { similar situation before }\end{array}$ & 16 & 21.9 & 15 & 20.5 & 25 & 34.2 & 17 & 23.3 \\
\hline $\begin{array}{l}\text { 49. I knew what had to be done, so I doubled my } \\
\text { efforts to make things work }\end{array}$ & 9 & 12.3 & 14 & 19.2 & 30 & 41.1 & 20 & 27.4 \\
\hline $\begin{array}{l}\text { 52. Came up with a couple of different solutions } \\
\text { to the problem }\end{array}$ & 8 & 11 & 17 & 23.3 & 32 & 43.8 & 16 & 21.9 \\
\hline \multicolumn{9}{|l|}{ 4.Positive reappraisal } \\
\hline 20. I was inspired to do something creative & 19 & 26 & 21 & 28.8 & 20 & 27.4 & 13 & 17.8 \\
\hline 23.Changed or grew as a person in a good way & 12 & 16.4 & 22 & 30.1 & 27 & 37 & 12 & 16.4 \\
\hline $\begin{array}{l}\text { 30. I came out of the experience better than when } \\
\text { I went in }\end{array}$ & 7 & 9.6 & 20 & 27.4 & 28 & 38.4 & 18 & 24.7 \\
\hline 36. Found new faith & 13 & 17.8 & 19 & 26 & 30 & 41.1 & 11 & 15.1 \\
\hline 38.Rediscovered what is important in life & 7 & 9.6 & 13 & 17.8 & 30 & 41.1 & 23 & 31.5 \\
\hline 56. I changed something about myself & 5 & 6.8 & 20 & 27.4 & 33 & 45.2 & 15 & 20.5 \\
\hline 60.I prayed & 6 & 8.2 & 15 & 20.5 & 20 & 27.4 & 32 & 43.8 \\
\hline \multicolumn{9}{|l|}{ Emotion based strategies } \\
\hline \multirow[t]{2}{*}{ 1.Distancing } & \multicolumn{2}{|c|}{ Not used } & \multicolumn{2}{|c|}{$\begin{array}{l}\text { Used } \\
\text { somewhat }\end{array}$} & \multicolumn{2}{|c|}{$\begin{array}{l}\text { Used quite a } \\
\text { bit }\end{array}$} & \multicolumn{2}{|c|}{$\begin{array}{l}\text { Used a great } \\
\text { deal }\end{array}$} \\
\hline & No. & $\%$ & No. & $\%$ & No. & $\%$ & No. & $\%$ \\
\hline $\begin{array}{l}\text { 12. Went along with fate; sometimes I just have } \\
\text { bad luck }\end{array}$ & 13 & 17.8 & 24 & 32.9 & 23 & 31.5 & 13 & 17.8 \\
\hline 13.Went on as if nothing had happened & 24 & 32.9 & 24 & 32.9 & 13 & 17.8 & 12 & 16.4 \\
\hline $\begin{array}{l}\text { 15.Looked for the silver lining, so to speak; tried } \\
\text { to look to the bright side of things }\end{array}$ & 7 & 9.6 & 17 & 23.3 & 31 & 42.5 & 18 & 24.7 \\
\hline 21.Tried to forget the whole thing & 20 & 27.4 & 21 & 28.8 & 21 & 28.8 & 11 & 15.4 \\
\hline $\begin{array}{l}\text { 41.Didn't let it get to me; refused to think too } \\
\text { much about it }\end{array}$ & 10 & 13.7 & 24 & 32.9 & 23 & 31.5 & 16 & 21.9 \\
\hline $\begin{array}{l}\text { 44. Made light of the situation; refused to get too } \\
\text { serious about it }\end{array}$ & 23 & 31.5 & 23 & 31.5 & 21 & 28.8 & 6 & 8.2 \\
\hline \multicolumn{9}{|l|}{ 2.Self-controlling } \\
\hline $\begin{array}{l}\text { 10. Tried not to burn my bridges, but leave things } \\
\text { open somewhat }\end{array}$ & 19 & 26 & 18 & 24.7 & 26 & 35.6 & 10 & 13.7 \\
\hline 14. I tried to keep my feelings to myself & 7 & 9.6 & 13 & 17.8 & 29 & 39.7 & 24 & 32.9 \\
\hline $\begin{array}{l}\text { 35. I tried not to act too hastily or follow my first } \\
\text { hunch }\end{array}$ & 20 & 27.4 & 24 & 32.9 & 19 & 26 & 10 & 13.7 \\
\hline $\begin{array}{l}\text { 43. Kept others from knowing how bad things } \\
\text { were }\end{array}$ & 16 & 21.9 & 17 & 23.3 & 24 & 32.9 & 16 & 21.9 \\
\hline $\begin{array}{l}\text { 54. I tried to keep my feelings from interfering } \\
\text { with other things too much }\end{array}$ & 6 & 8.2 & 19 & 26 & 30 & 41.1 & 18 & 24.7 \\
\hline $\begin{array}{l}\text { 63. I thought about how a person I admire would } \\
\text { handle this situation and used that as a model }\end{array}$ & 33 & 45.2 & 16 & 21.9 & 18 & 24.7 & 6 & 8.2 \\
\hline
\end{tabular}


Impact of Usage of Different Coping Strategies on Academic Performance of Female Students...

\begin{tabular}{|c|c|c|c|c|c|c|c|c|}
\hline \multicolumn{9}{|l|}{ 3.Accepting responsibility } \\
\hline 9. Criticized or lectured myself & 7 & 9.6 & 16 & 21.9 & 22 & 30.1 & 28 & 38.4 \\
\hline 25. I apologized or did something to make up & 23 & 31.5 & 20 & 27.4 & 24 & 32.9 & 6 & 8.2 \\
\hline 29. Realized I brought the problem on myself & 14 & 19.2 & 21 & 28.8 & 17 & 23.3 & 21 & 28.8 \\
\hline $\begin{array}{l}51 . \text { I made a promise to myself that things would } \\
\text { be different next time }\end{array}$ & 5 & 6.8 & 10 & 13.7 & 32 & 43.8 & 26 & 35.6 \\
\hline \multicolumn{9}{|l|}{ 4.Escape-Avoidance } \\
\hline 11. Hoped a miracle would happen & 13 & 17.8 & 11 & 15.1 & 21 & 28.8 & 28 & 38.4 \\
\hline 16. Slept more than usual & 11 & 15.1 & 21 & 28.8 & 14 & 19.2 & 27 & 37 \\
\hline $\begin{array}{l}\text { 33. Tried to make myself feel better by eating, } \\
\text { drinking, smoking, using drugs or medication }\end{array}$ & 28 & 38.4 & 19 & 26 & 10 & 31.7 & 16 & 21.9 \\
\hline 40. Avoided being with people in general & 17 & 23.3 & 19 & 26 & 17 & 23.3 & 20 & 27.4 \\
\hline 47. Took it out on other people & 35 & 47.4 & 19 & 26 & 13 & 17.8 & 6 & 8.2 \\
\hline 50. Refused to believe that it had happened & 33 & 45.2 & 20 & 27.4 & 13 & 17.8 & 7 & 9.6 \\
\hline $\begin{array}{l}\text { 58. Wished that the situation would go away or } \\
\text { somehow be over with }\end{array}$ & 5 & 6.8 & 11 & 15.1 & 29 & 39.7 & 28 & 38.4 \\
\hline
\end{tabular}

\begin{tabular}{|l|l|l|l|}
\hline Table 4: coping strategies order in use & Mean & Rank order \\
\hline Strategies & 13.3836 & 55.83 & 8 \\
\hline 1.Confrantive coping & 13.6301 & 56.667 & 7 \\
\hline 2.Seeking social support & 16.6027 & 69.7 & 2 \\
\hline 3.Planful problem solving & 21.5205 & 76.86 & 1 \\
\hline 4.Positive reappraisal & 14.5616 & 60.83 & 6 \\
\hline 5.Distancing & 14.9178 & 62.08 & 5 \\
\hline 6.Self-control & 10.8493 & 67.5 & 3 \\
\hline 7.Accepting responsibility & 20.2466 & 63.28 & 4 \\
\hline 8.Escape-Avoidance & & & \\
& & & \\
\hline
\end{tabular}

According to table 4, positive reappraisal was the most used strategy by the students as the percentage was $76.86 \%$ and the mean was 21.5205 while, confrontive coping was the least to use as the percentage was $55.83 \%$ and the mean was 13.3836 , other strategies were ranked as following: positive reappraisal, planful problem solving, accepting responsibility, escape-avoidance, self-control, distancing, seeking social support and lastly confrontive coping.

Table 5: association between GPA and (Family type, , family income and year of study)

\begin{tabular}{|l|l|c|}
\hline Variable & Chi-square & P value \\
\hline Family type & 7.498 & 0.058 \\
\hline Family income & 6.314 & 0.389 \\
\hline Year of study & 13.020 & 0.601 \\
\hline
\end{tabular}

By using Chi-square test, there was no significant association between GPA and family type, family income and year of study as the $\mathrm{P}$ value were $=0.058,0.389$ and 0.601 respectively also, by using the same test, there was no significant association between GPA and each of coping strategies addressed in this study. On the other hand, multiple different associations were noticed. Regarding marital status there were an association with sleeping more than usual $(\mathrm{P}$ value $=0.002)$ which was a part of escape-avoidance, another association was with trying to forget the whole thing ( $\mathrm{P}$ value $=0.011)$; it is a part of distancing strategy, also an association had been noticed with trying to keep feelings from interfering with other things too much $(\mathrm{P}$ value $=0.003)$ which is a part of self-controlling. Regarding having children there was an association between not having children and I went over in my mind what I would say or do point $(\mathrm{P}$ value $=0.016)$ which is a part of confrontive coping. Regarding family income, an association found to be with inspiring to do something creative $(\mathrm{P}$ value $=0.009)$ which was a part of positive reappraisal. Regarding family type, there was an association between living in nuclear family and trying to make oneself feel better by eating, drinking, smoking, using drugs or medication, etc. ( $\mathrm{P}$ 
value $=0.023)$ which was a part of escapeavoidance.

Regarding educational level, many significant associations had been noticed, at first, an association between being in the third year or an intern and with talking to someone to find out more about the situation $(\mathrm{P}$ value $=$ 0.03) which was a part of seeking social support, second: an association with criticizing or lecturing oneself $(\mathrm{P}$ value $=0.018)$ which was a part of accepting responsibility, third association was with expressing anger to the person(s) who caused the problem ( $\mathrm{P}$ value $=$ 0.012) which was a part of confrontive coping.

The forth association was with changing or growing as a person in a good way point $(\mathrm{P}$ value $=0.01)$ which was a part of positive reappraisal, the fifth association was taking a big chance or doing something very risky $(\mathrm{P}$ value $=0.008)$ which was a part of confrontive coping, the sixth association was with asking a respected relative or friend for advice $(\mathrm{P}$ value $=0.021)$ which was a part of seeking social support, the seventh association was with keeping others from knowing how bad things (P value: .038) which was a part of self-control.

The eighth association was with refusing to believe that the stressful situation had occurred $(\mathrm{P}$ value $=0$.012) which was a part of escape-avoidance, the ninth association was with having fantasies or wishes about how things might turn out $(\mathrm{P}$ value $=0.045)$ which is a part of escape-avoidance also. the last association was having thoughts about how a person the student admire would handle this situation and used that as a model $(\mathrm{P}$ value $=0.01$ ) which is a part of self-control. Regarding studying hours, studying from three to five hours was associated with doing something which the student didn't think it would work, but at least doing something $(\mathrm{P}$ value $=0.016$ ) which is a part of confrontive coping, also this had significant association with coming out of the experience as better than when the student went in $(\mathrm{P}$ value $=0.05)$ which is a part of positive reappraisal, the third association was with talking to someone who could do something concrete about the problem $(\mathrm{P}$ value $=0.033)$ which is a part of seeking social support .The forth association was with taking a big chance or doing something very risky $(\mathrm{P}$ value $=0.034)$ which is a part of confrontive coping, the fifth association was with having fantasies or wishes about how things might turn out $(\mathrm{P}$ value $=0.046)$ which is a part of escapeavoidance, the last association was with prying $(\mathrm{P}$ value $=0.00)$ which is a part of positive reappraisal.

\section{Discussion:}

As a student, being sad, upset and depressed this can significantly affect his academic performance. According to the results of our study, 58.9\% reported that they being upsetlsad for significant amount in 2 weeks' period, $21.9 \%$ were not sure about their feelings and 19.2 only didn't report any sad feelings which was more than what has been reported by a study done in Cameroon in 2017, which showed that $30.6 \%$ were found to have major depressive disorder (PHQ Score $\geq 10$ ). (34.6\%) of them considered to have mild form, (26.4\%) having moderate form, $(3.4 \%)$ having moderately severe and $(0.80 \%)$ students were classified as having severe depression (14). Another Meta-analysis showed that the prevalence of depressive symptoms among medical students was $27.2 \%$ and $11.1 \%$ having suicidal thoughts ${ }^{(15)}$. But, we can't consider our study to have increased depressive symptoms prevalence as we didn't use the DSM5 criteria in our survey so it could be only a normal acute sadness that anyone can came through in his life.

An intersecting finding in this study, there was an association between marital status and emotion focused coping strategies specifically being single makes the student uses emotion focused coping strategies more than problem focused coping strategy as there was a significant association with sleeping more than usual point ( $\mathrm{P}$ value: .002) which was a part of avoidance, also another association was trying to forget the whole thing (P value: .011) which was considered as a distancing strategy point. Finally, being single was associated with more usage trying to keep feelings from interfering with other things too much (P value: .003) which was a part of self-controlling and all of these three strategy considered as emotion based strategies. No previous studies correlate marital status with emotional focused strategies.

Regarding educational level, it seemed that in the third year before you enter the clinical years or being in the internship before graduation makes students use the different 
strategies in an equal manner as there was an equal distribution in the use of strategies and this was also reported in a study published in 2017 as over time and especially during the 3rd year, medical students decrease their use of active coping strategies and increase their use of emotional strategies which makes them equal eventually ${ }^{(14)}$. Regarding studying hours, there was no significant association with academic performance ( $\mathrm{P}$ value: .63), it's worth mentioning that here in our study $50.7 \%$ of the students were studying only for three to five hours and also, it was reported in a study published in 2014 that there was a positive association between GPA and working up to about five hours then there was a declining relationship between grades and working (16). This may be due to loose of concentration and exhaustion from long studying hours, which make the student enable to function in a good way. According to the results of our study, studying from three to five hours were significantly associated with more usage of active problem based strategies. This may due to that, they were not putting themselves under a lot of pressure by long studying hours which eventually affect their judgment and how they can handle the stressful encounter by an active way. Finally, we can't consider this study for assessment of coping style and if we want to assess the styles we should do an observational study and redistribute the survey again on the same students who respond in the first time in different accessions.

\section{Conclusion:}

Academic stress can present in any specialty but medicine in specific is one of the most stressful fields due to its highly demanding professional and academic requirements. This usually leads to decrease attention and concentration, impairing decision-making, emotional exhaustion and finally burnout. To overcome this, students use different coping strategies some of them problem based and others are emotion based strategies. According to our study, there was no significant difference either the student use an emotion based or active approach if he will use it in a good way and it will lead him to success eventually. Being single in general may lead you to the use of more emotion based strategies rather than active problem based strategies. Studying from 3 to 5 hours also has been associated with the use of more active strategies.

Growing and being in the third year at the beginning of clinical years and in final year (internship) makes the student balanced in the use of different strategies.

\section{References:}

1. Xiao JT (2013): Academic stress, test anxiety, and performance in a Chinese high school sample: The moderating effects of coping strategies and perceived social support. Dissertation, Georgia State University.

2. Waqas A, Khan S, Sharif W, Khalid U and Ali A (2015): Association of academic stress with sleeping difficulties in medical students of a Pakistani medical school: a cross sectional survey. PeerJ., 3: P840.

3. Fawzy M and Hamed S (2017): Prevalence of psychological stress, depression and anxiety among medical students in Egypt. Psychiatry Research., 255:186-194.

4. Vaillant GE, Sobowale NC and MacArthur C (1972): Some psychological vulnerabilities of physicians., N Engl J Med., 278:372-375.

5. McCue JD (1982): The effects of stress on physicians and their medical practice. N Engl J Med., 306(8):458-463.

6. Schiller JH, Stansfield RB, Belmonte DC, Purkiss JA, Reddy RM, House JB and Santen SA (2018): Medical students' use of different coping strategies and relationship with academic performance in preclinical and clinical years. Teaching and Learning in Medicine, 30(1):15-21.

7. Dyrbye LN, Thomas MR, Massje FS, Power DV, Eacker A, Harper W, Durning C, Moutier C, Szydlo DW, Novotny PJ, Sloan JA and Shanafelt TD ( 2008): Burnout and suicidal ideation among US medical students. Ann Intern Med., 149:334-341.

8. Firth J (1986): Levels and sources of stress in medical students. $\mathrm{Br}$ Med J., 292(6529):1177-1180.

9. Chowdhury R, Mukherjee A, Mitra K, Naskar S, Karmakar PR and Lahiri SK (2017): Perceived psychological stress among undergraduate medical students: Role of academic factors. Indian $\mathrm{J}$ Public Health, 61(1): 55-57.

10. Saipanish $R$ (2003): Stress among medical students in a Thai medical school. Medical Teacher., 25(5):502-506. 
11. Folkman S, Lazarus RS, DunkelSchetter C, DeLongis A., and Gruen RJ (1986): Dynamics of a stressful encounter: Cognitive appraisal, coping, and encounter outcomes. J Pers Soc Psychol., 50(5):9921003.

12. Wegner DM and Erber $R$ (1992): The hyperaccessibility of suppressed thoughts. J Pers Soc Psychol., 63(6):903-912.

13. Sohail N (2013): Stress and academic performance among medical students. J Coll Physicians Surg Pak., 23(1): 67-71.

14. Ádám S, Nistor $A$, Nistor $K$ and Hazag A (2014): Negative and positive predictive relationships between coping strategies and the three burnout dimensions among Hungarian medical students. Orv Hetil., 155(32): 12731280.

15. Rotenstein LS, Ramos MA, Torre M., Segal JB, Peluso MJ, Guille $\mathrm{C}$, Sen $\mathrm{S}$ and Mata DA (2016): Prevalence of Depression, Depressive Symptoms, and Suicidal Ideation Among Medical Students: A Systematic Review and Meta-Analysis. JAMA., 316(21): 2214-2236.

16. Darolia R (2014): Working and studying day and night: Heterogeneous effects of working on the academic performance of fulltime and part-time students. Economics of Education Review, 38(C): p 38-50. 